Article

\title{
Life Cycle Assessment on a Biorefinery Approach to Pyrolysis Oil for Wood Modification Treatment
}

\author{
Jurjen Spekreijse ${ }^{1, *}$, Tobias Weide ${ }^{2,3}\left(\mathbb{D}\right.$, Simon P. W. Hageman ${ }^{4}$, Patrick Reumerman ${ }^{1}$, \\ Christof Wetter ${ }^{2,3}$, Elmar Brügging ${ }^{2,3}$ and Martijn Vis ${ }^{1}$ \\ 1 BTG Biomass Technology Group, P.O. Box 835, 750O AV Enschede, The Netherlands; \\ reumerman@btgworld.com (P.R.); vis@btgworld.com (M.V.) \\ 2 Faculty of Energy Building Services Environmental Engineering, Münster University of Applied Sciences, \\ 48149 Münster, Germany; tobias.weide@fh-muenster.de (T.W.); wetter@fh-muenster.de (C.W.); \\ bruegging@fh-muenster.de (E.B.) \\ 3 Institute association for Resources, Energy and Infrastructure, Münster University of Applied Sciences, \\ 48149 Münster, Germany \\ 4 Sustainable Energy Systems, Saxion University of Applied Sciences, P.O. Box 70.000, 7500 KB Enschede, \\ The Netherlands; s.p.w.hageman@saxion.nl \\ * Correspondence: spekreijse@btgworld.com
}

Received: 10 September 2019; Accepted: 8 October 2019; Published: 10 October 2019

check for updates

\begin{abstract}
The use of pyrolysis-based wood conservation is a good alternative for the use of fossil-based creosotes. In this life cycle assessment (LCA) the environmental impact of a biorefinery approach of pyrolysis oil from forestry residues or maize digestate and its application as wood modification treatment is determined. The damage to ecosystems, damage to human health and the increased resource scarcity is studied using an attributional LCA and a sensitivity and uncertainty analysis. Based on data from an existing pyrolysis plant, it is shown that pyrolysis oil from maize digestate has a significantly higher environmental impact than pyrolysis oil from forestry residues. This is due to a lower energetic yield and a higher ash content in the feedstock. The biorefinery approach of using pyrolytic sugars as wood modification treatment shows significantly lower environmental impacts than the fossil-based creosotes, regardless of the selected end of life scenario, due to a lower toxicity and by a reduction of $82 \%$ of greenhouse gases. This shows that in addition to energy production, pyrolysis oil can be applied as biobased chemicals and materials, developing a sustainable platform based on pyrolysis oil.
\end{abstract}

Keywords: pyrolysis; biorefinery; wood modification; LCA; biobased; creosote

\section{Introduction}

Creosote is widely used as a wood preservative for railroad ties, telephone poles and bridge timbers and is produced by using wood tar and coal tar [1]. Wood creosote is mainly used for pharmaceutical purposes whereas coal tar creosote is used for wood treatment. Coal tar creosote is an oily liquid and is produced by the fractional distillation of crude coal tars [2]. Depending on the process conditions, the composition consists of several hundred compounds, which can be divided into six classes: (1) Aromatic hydrocarbons, including polycyclic aromatic hydrocarbons (PAHs) and alkylated PAHs; (2) tar acids and phenolic resins; (3) tar bases; nitrogen-containing heterocycles; (4) aromatic amines; (5) sulfur-containing heterocycles; and (6) oxygen-containing heterocycles, including dibenzofurans [3].

Due to environmental risks, the European Parliament has restricted the use of creosote since April 1st, 2013 [4]. In spite of this, the demand for wood preservation remains enormous, necessitating the development of alternative methods of environmentally acceptable preservation technologies [5]. 
Fast pyrolysis is a technique that produces a homogeneous liquid from biomass by rapidly heating the biomass to $400-600{ }^{\circ} \mathrm{C}$ in the absence of oxygen. Pyrolysis liquid, also called pyrolysis oil due to its oily appearance, can be directly applied for combustion to energy, or it can be upgraded to biofuel or biochemicals [6-9]. During the process, a complex mixture of mostly liquid components is formed, with a small amount of char and non-condensable gases. Due to the complexity of the mixture, the interactions between components, potential heat transport limitations, and the short lifespan of some of the components, the kinetics of pyrolysis is not yet fully understood and may change depending on the type of feedstock [6].

Several technologies have been developed aiming to concentrate the energetic value of biomass in a homogeneous, rather stable, pumpable liquid, while removing the ash. The remaining energy, e.g., from the non-condensable gases, can be used for the production of bioenergy [10]. For example, Ensyn has developed a rapid thermal processing (RTP) technology in North America, using a circulating fluid bed system. Dynamotive Technologies acquired a pyrolysis technology on the basis of indirect heating of a fluidized bed. In Europe, VTT has developed a pyrolysis technology based on the integration of fast pyrolysis into a fluidized bed reactor, combining the pyrolysis with a combined heat and power (CHP) plant [10]. Finally, BTG developed a pyrolysis technique based on a rotating cone. The simplification of this reactor design eases the scaling-up process, which is highlighted by the announcement of several pyrolysis plants being constructed in Scandinavia using this technique [11].

While these technologies focus on the use of pyrolysis oil for energy purposes, within the Horizon2020 project, Bio4Products aims at developing a technology to divide pyrolysis oil into multiple fractions that could be used for material applications. Many new products could be developed from pyrolysis; an example is the separation of pyrolysis oil into two fractions, a pyrolytic sugar fraction and a pyrolytic lignin fraction. The lignin fraction could find applications in phenolic resin substitution, where the pyrolytic sugar fraction could substitute creosotes as a wood modification treatment.

Research in the field of rapid pyrolysis and product analysis of creosote treated woods is limited [12]. Especially when it comes to life cycle assessment (LCA) studies there are few studies concerning creosote alternatives. [13]. Moreover, current LCA studies are based only on modeling data [14-18]. Therefore, little is known on the sustainability of using pyrolysis oil for material applications based on data originating from a demoplant scale operation. This study aims to determine the sustainability of replacing fossil creosote by biobased pyrolysis oil fractions for wood modification via an LCA methodology. This allows for the determination of the sustainability of this particular biobased application, as well as validating previous sustainability assessments on pyrolysis oil using real factory data. With the expectation that many more biobased products will be developed using pyrolysis oil or pyrolysis oil fractions, this study provides the principle of the pyrolysis oil platform and useful data from future sustainability assessments.

In order to assess the sustainability of the process, an LCA methodology was applied. LCA is a structured, standardized method that has been widely accepted to determine the impact of processes or services on humans, the environment and the depletion of resources [19]. Limitations of the LCA methodology are that different practitioners may have variations in practices. Therefore, the modeling choices, study boundaries and assumptions made in this LCA are clearly presented in the materials and methods section.

The sustainability of pyrolysis oil applications is likely to depend on the type of biomass feedstock. An alternative feedstock to the forestry residues that are commonly used in large scale pyrolysis processes could be maize digestate. Maize digestate is formed as a side product from the anaerobic digestion of maize and manure, a common practice to produce renewable energy in countries such as Germany [20]. This study investigates the use of maize digestate compared to forestry residues as feedstock for pyrolysis oil production and investigates the application of the sugar fraction from pyrolysis oil as a wood preservative treatment. In this application, the pyrolytic sugars that are be obtained by separating the pyrolysis oil fractions are intended to replace creosote. 
This article presents the results of the environmental impact evaluation, which consists of an LCA to compare the environmental impacts of the supply chain from biomass origin, pyrolysis oil production, pyrolysis fractionation to produce pyrolytic sugars, wood preservative treatment, use of the treated wood and the end of life of the treated wood. The LCA contains an analysis of 17 different environmental impacts clustered around three end points: Damage to human health, damage to ecosystems and damage to resources. The LCA provides quantitative insight in the environmental performance and possible environmental risks of the use of maize digestate for fast pyrolysis bio oil (FPBO), and the use of FPBO for wood preservative treatment.

Finally, the results are brought into the context of other studies and life cycle assessments on fast pyrolysis. In particular, studies on the use of residual biomass $[17,21]$, the use of woody biomass $[14,16]$ and the production of bio-fuel and chemicals $[15,16,22,23]$ are applied.

\section{Materials and Methods}

The LCA was performed in accordance to the International Organization for Standardization (ISO) 14040 and ISO 14044, using the International Reference Life Cycle Data System (ILCD) handbook as guidance, with the exception of the review process [24]. The review of this LCA was performed by a single external review (in addition to the peer review for this journal), rather than a panel review. The review was performed by Blonk Consultants and the review statement can be found in the Supplementary information (Document S3: LCA review statement by Blonk Consultants). Simapro version 8.5.2.0, released in May 2018, was used as the modeling software. Recipe 2016 was used as the impact assessment method, using the hierarchist perspective with a time horizon of 100 years.

The boundaries of the LCA were divided in two parts as shown in Figure 1. Firstly, to determine the impact of different feedstocks for the production of pyrolysis oil, the boundary was set in accordance with as a cradle-to-gate LCA. As functional unit $1 \mathrm{GJ}$ pyrolysis oil was selected. Secondly, to compare the use of fossil-based creosote to pyrolytic sugars, the boundary was set to encompass the entire system from feedstock to wood modification. Here, the functional unit was $1 \mathrm{~m}^{3}$ a of modified wood, i.e., $1 \mathrm{~m}^{3}$ of modified wood multiplied by the time of use of the modified wood in years. This included the production, use, and end of life of $1 \mathrm{~m}^{3}$ of wooden poles for 1 year.

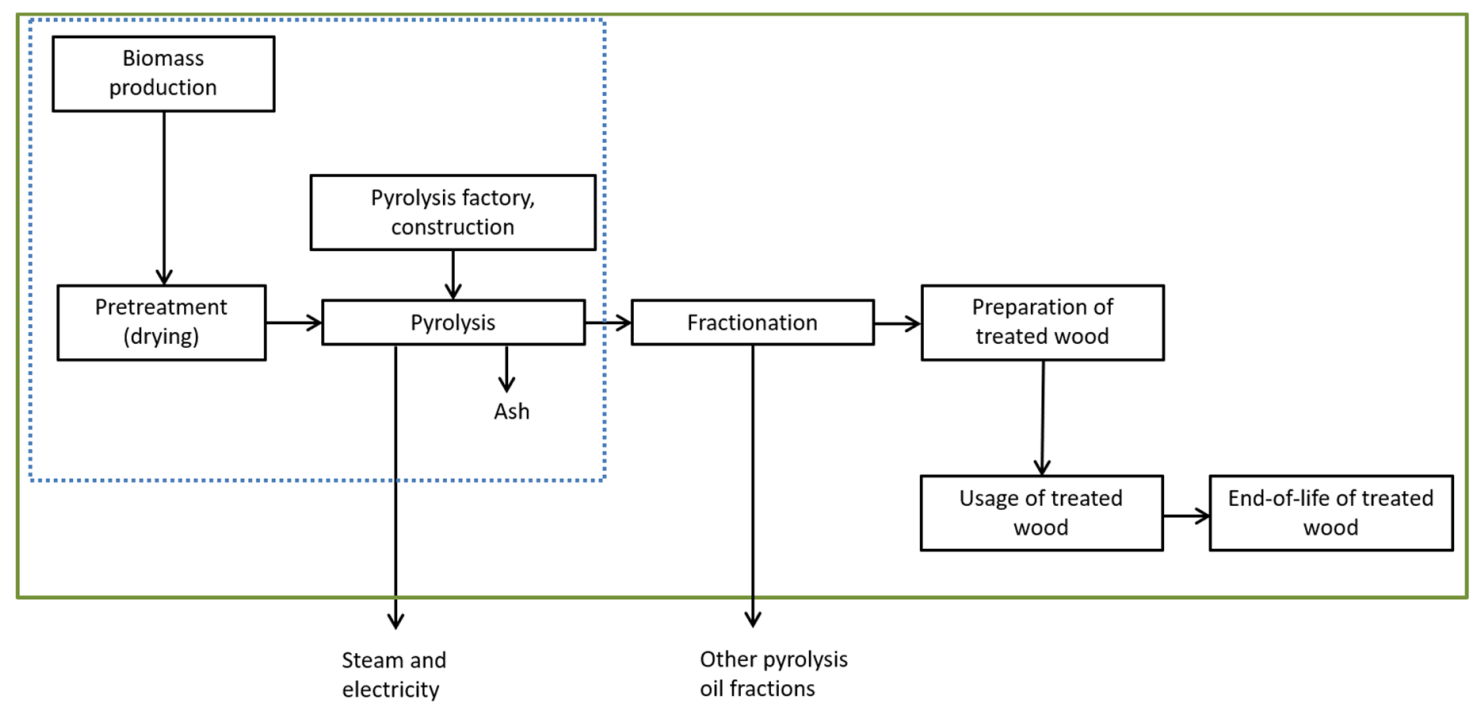

Figure 1. System boundaries of the life cycle assessment (LCA). Blue dotted line: The system boundaries of the pyrolysis oil LCA. Green solid line: The system boundaries of the wood modification LCA.

Life cycle inventory (LCI) data was obtained from within the Dutch-German Interreg project Groen Goud as well as the Horizon2020 projects Bio4Products and Residue2Heat. Additional data was obtained from open literature and the Ecoinvent database (version 3.4, compiled in April 2018). The LCI 
of creosote-based wood modification was based on the work of Bolin et al. [13] and Kohler et al. [25], where the end of life LCI was supplemented with data from Otten et al. [26].

The LCA was classified as category A (microlevel decision support), in accordance to the ILCD handbook, and set up as an attributional LCA. The co-production of steam and electricity was allocated on an energy basis, where the coproduction of multiple fractions from pyrolysis oil was allocated on a mass-basis. The uncertainty analysis was performed by a Monte Carlo analysis with 10.000 calculations, results were deemed significantly different when there is no overlap between the $95 \%$ confidence interval of both numbers. The impact of the assumed end of life of the modified wood was researched by a sensitivity analysis on the end of life.

\section{Results}

The main results that impact the conclusions of the LCA are presented here. First, a selection of biomass feedstock was made based on a cradle to gate analysis. From this analysis the biomass feedstock with the lowest environmental impact was selected to be compared with the fossil-based creosotes. This impact was assessed on 18 midpoints, such as greenhouse gas emissions (in $\mathrm{CO}_{2}$ equivalents), land use (in $\mathrm{m}^{2}$ a crop equivalents), etc. A full list of all 18 impacts at midpoint level is presented in the Supplementary Information (SI), with in Table S1 the values for the pyrolysis oil value chain and in Table S2 the values for the treated wooden pole value chain. These midpoints were then summed in three final endpoints: Damage to ecosystems, damage to human health and resource scarcity, following the ReCiPe 2016 methodology [27].

\subsection{Impact of the Use of Different Biomass Feedstocks on Pyrolysis Oil in a Cradle to Gate Analysis}

To understand the impact of replacing the biomass feedstock for pyrolysis from forestry residues with maize digestate, the endpoint scores were determined in a cradle to gate analysis of pyrolysis oil. The difference in impact of $1 \mathrm{GJ}$ pyrolysis oil produced from maize digestate and forestry residues is presented in Figure 2.

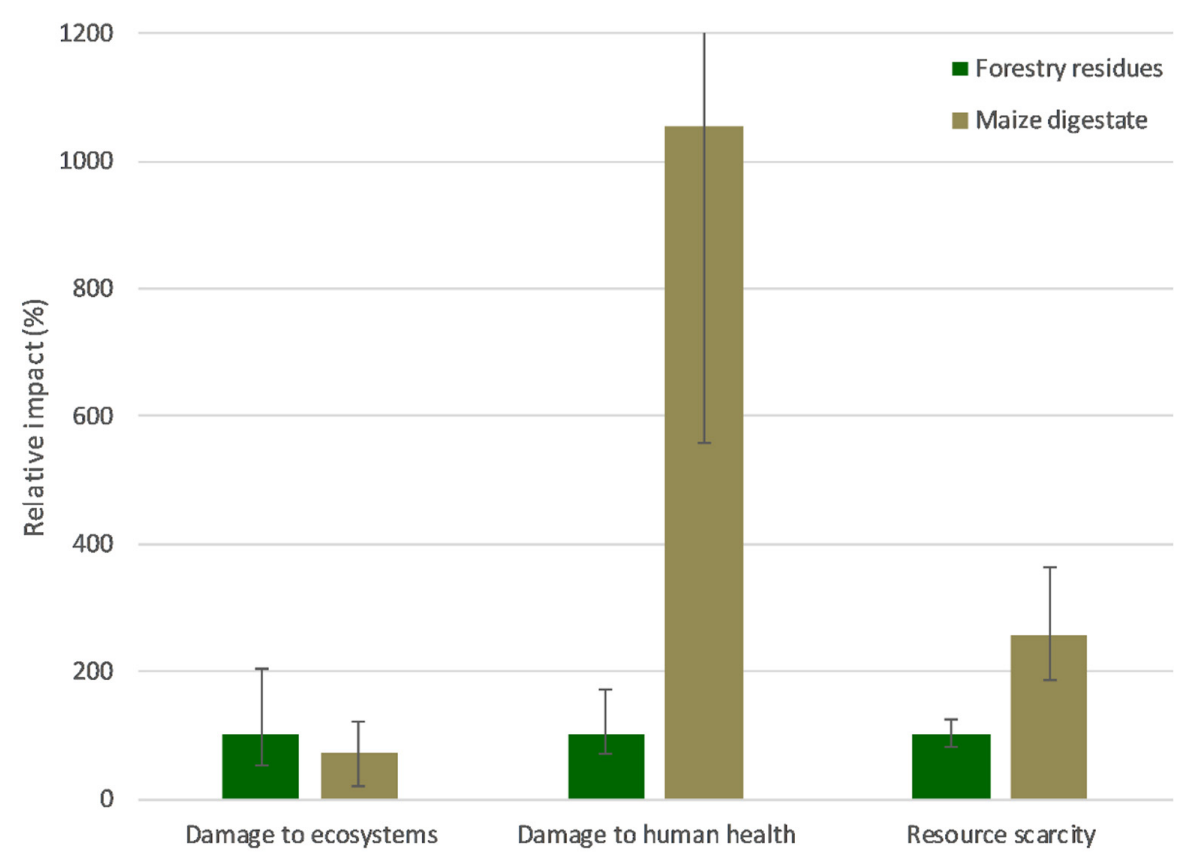

Figure 2. Relative environmental impact of $1 \mathrm{GJ}$ pyrolysis oil from maize digestate compared to forestry residues. The impact of forestry residues was set at 100\%. Error bars represent the $95 \%$ confidence interval from the Monte Carlo analysis of 10.000 calculations. The error bar for the impact on human health of pyrolysis oil from maize digestate was cut off at $1200 \%$, the total value was $2239 \%$. 
As shown in Figure 2, the impact on damage to ecosystems from pyrolysis oil did not change significantly when a different feedstock was used for the production. However, there was a significantly larger impact on human health and on resource scarcity when maize digestate was used over forestry residues. The total impact on human health was more than ten times higher for pyrolysis from maize digestate than for pyrolysis from forestry residues. Moreover, pyrolysis from maize digestate increased the fossil resource scarcity by a factor of 2.5. Since pyrolysis oil from forestry residues led to lower overall environmental impacts, this system was further developed to include the wood modification process.

\subsection{Impact of Wood Modification Treatment by Using Pyrolysis Oil}

The impact of wood modification treatment by pyrolysis oil was compared to the impact of wood modification treatment by creosotes. The overall impact is shown for $1 \mathrm{~m}^{3}$ a treated wood, i.e., the production, use and end of life of $1 \mathrm{~m}^{3}$ of wooden poles for 1 year. The environmental impacts are presented in Figure 3.

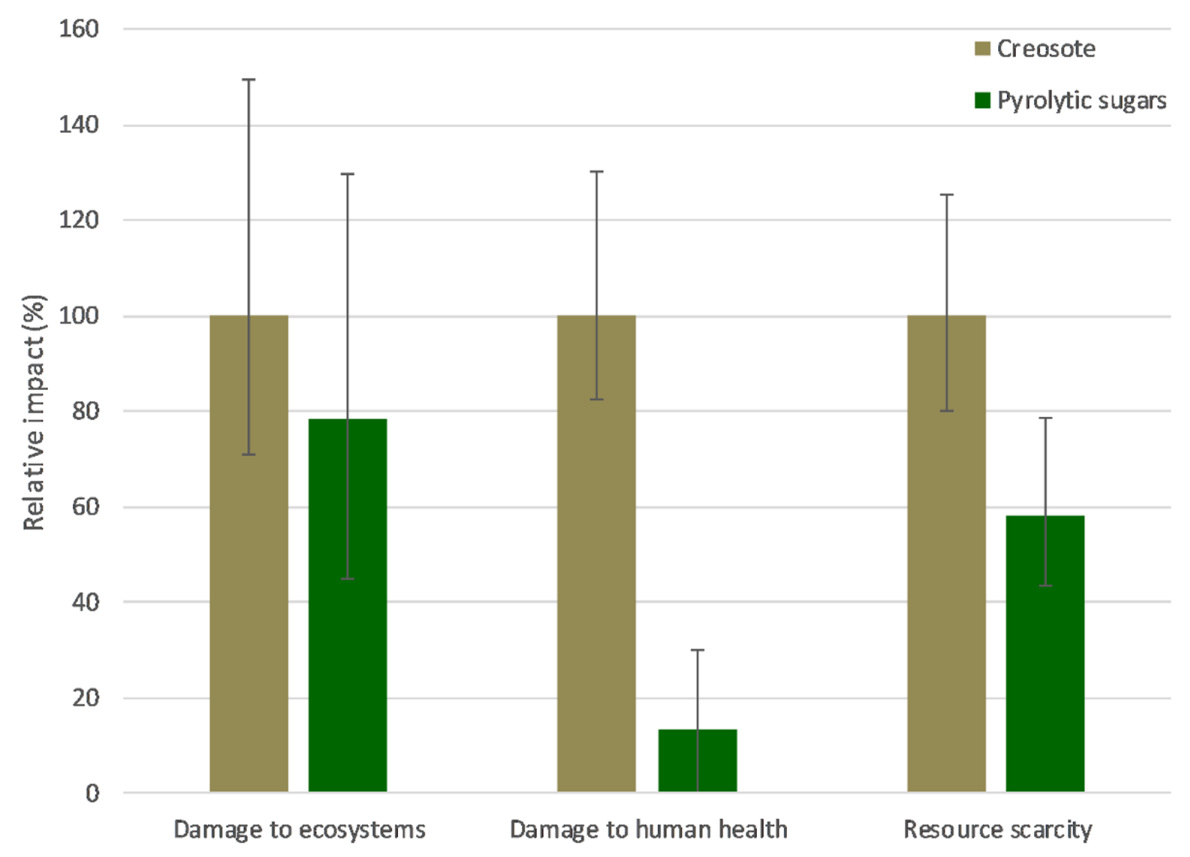

Figure 3. Relative environmental impact of $1 \mathrm{~m}^{3}$ a pyrolytic sugar treated wooden poles compared to creosote treated wooden poles. Error bars represent the $95 \%$ confidence interval.

The currently used method, the creosote treatment, was set at $100 \%$ in order to compare the impact of the treatment with pyrolytic sugars. The damage to ecosystems did not show a significantly different impact. However, the impact on resource scarcity was significantly lower. The largest difference could be found in the endpoint of damage to human health, where the treatment with pyrolytic sugars only caused $10 \%$ of the total damage to human health of creosote treatment.

\subsection{Impact of the End of Life of Modified Wooden Poles}

In order to ensure that the LCA describes the impact of the different treatment methods, the impact of the selected end of life option was investigated with a sensitivity analysis. In the LCA, it was assumed that the wooden pole would be sent to an incineration after use. However, a landfill is also a common waste treatment method. By changing the amount of product sent to a landfill in three scenarios (1\%, 50\% and 99\%), the impact of the choice of end of life could be determined. The remainder that is not sent to the landfill is incinerated. By calculated the differences between 
the two wood modification processes, the influence of the end of life scenario on the difference in environmental impact of the two systems can be determined. The results are presented in Table 1.

Table 1. Impact of end of life scenario on the endpoint scores of $1 \mathrm{~m}^{3}$ a pyrolytic sugar treated wooden poles.

\begin{tabular}{cccc}
\hline Amount Sent to Landfill & $\begin{array}{c}\text { Difference in Impact to } \\
\text { Ecosystems (Species } \times \text { Year) }\end{array}$ & $\begin{array}{c}\text { Difference in Impact to } \\
\text { Human Health (DALY }{ }^{\mathbf{1}} \text { ) }\end{array}$ & $\begin{array}{c}\text { Difference in Impact Resource } \\
\text { Scarcity (USD 2013 }{ }^{2} \text { ) }\end{array}$ \\
\hline $1 \%$ & $0.52 \times 10^{-7}$ & $4.71 \times 10^{-5}$ & 0.40 \\
\hline $50 \%$ & $0.42 \times 10^{-7}$ & $4.34 \times 10^{-5}$ & 0.35 \\
\hline $99 \%$ & $0.32 \times 10^{-7}$ & $3.97 \times 10^{-5}$ & 0.29 \\
\hline
\end{tabular}

Differences were calculated by subtracting the impact of $1 \mathrm{~m}^{3}$ a wooden poles treated with pyrolytic sugars from 1 $\mathrm{m}^{3} \mathrm{a}$ wooden poles treated with creosotes. ${ }^{1}$ DALY $=$ disability adjusted life years, and ${ }^{2}$ USD2013 is the value of the US dollar in 2013.

In Table 1, it can be seen that the differences in total impact stayed within the same order of magnitude for each of the three impact categories. Thus, the end of life scenario had no effect on the conclusions, and it could be ensured that the conclusions on this LCA described the differences in the treatment process rather than the impact of the end of life.

\section{Discussion}

For the production of pyrolysis oil two feedstocks were compared, forestry residues and maize digestate. The most striking result in this comparison was a higher impact on damage to human health and a significant increase in resource scarcity for maize digestate. The large change in impact could be explained by a couple of aspects of the processes. First, the pyrolysis oil yield on maize digestate was lower. Second, maize digestate contained more ash than forestry residues (30\% for maize digestate vs. $2.0 \%$ for forestry residues). Third, the energetic value of the pyrolysis oil from maize digestate was lower $(13.1 \mathrm{MJ} / \mathrm{kg})$ than for pyrolysis oil from forestry residues $(16.0 \mathrm{MJ} / \mathrm{kg})$. The lower yield in both material and energetic aspect resulted in a higher amount of maize digestate required for the production of the same energetic value in pyrolysis oil. This resulted in more transport of feedstock. Together with the higher requirements of ash treatments, these factors resulted in higher environmental impacts.

Further, regarding the comparison of the use of pyrolytic sugars compared with the fossil-based creosotes, unsurprisingly, the bio-based wood modification had a lower impact on resource scarcity than using creosotes. Moreover, due to the toxic nature of creosotes, the impact on human health was significantly larger for the use of creosotes than when the pyrolytic sugars were used. The small difference in damage to ecosystems could be explained by the fact that this impact factor was dominated by the impact of the land use required to fabricate the wooden pole itself.

The determined environmental impact of pyrolysis oil could be brought into context of other studies and life cycle assessments. However, the calculations in these studies were based on models rather than real practice. Moreover, the feedstock was often different, and the geographical boundaries were often outside of Europe. Since most LCAs focus on global warming, the greenhouse gas (GHG) emission of pyrolysis oil from this study was compared to the GHG emissions from other studies (Figure 4).

In Figure 4, the results of this LCA were compared to two other published LCAs. In the work of Dang et al., the impact of biofuel from corn from pyrolysis oil, using corn stover in the US as feedstock is calculated at $28.83 \mathrm{~g} \mathrm{CO}_{2}$ eq per MJ biofuel, which translates to $353 \mathrm{~g} \mathrm{CO}_{2} \mathrm{eq} /$ tonne pyrolysis oil [16]. This is similar to our result of $376 \mathrm{~g} \mathrm{CO}_{2}$ eq for 1 tonne of pyrolysis oil from forestry residues. A second study shows an impact of $30 \mathrm{~g} \mathrm{CO}_{2}$ eq per MJ biofuel based on pyrolysis oil from horse manure. In this study, a tail gas reactive pyrolysis is modeled on horse manure to produce aviation fuel and phenol. This would result in a GHG emission of $11 \mathrm{~g} \mathrm{CO}_{2}$ eq per tonne pyrolysis oil [17]. This impact is significantly lower since no impacts are considered from the horse manure 
and the phenol replaces petroleum-based phenol. Finally, two other studies on the use of pyrolysis oil as biofuel from Spain include a large $\mathrm{CO}_{2}$ uptake from the biomass production, which leads to a large negative emission $[14,15]$. This makes it impossible to compare these two results with the results presented in this LCA. Overall, the GHG emissions in this study, using real data from a demoplant scale operation, are of similar or even higher level than other reported LCA studies.

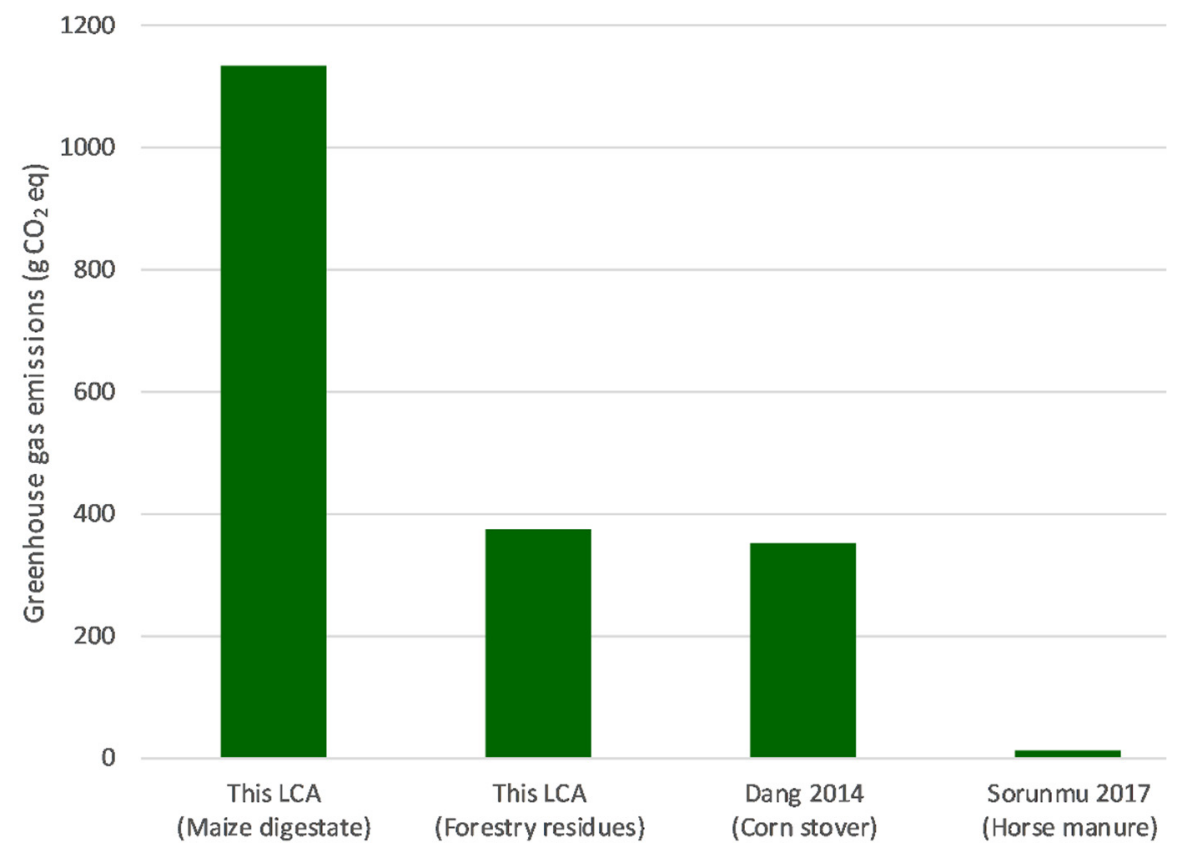

Figure 4. Greenhouse gas emission converted to $\mathrm{g} \mathrm{CO}_{2}$ equivalents per 1 tonne pyrolysis oil. Studies with a negative greenhouse gas (GHG) emission were excluded.

There are only a few public LCAs with sufficient LCI data on wood modification. This LCA was the first on the environmental impact of the use of pyrolytic sugars for wood modification. For the use of creosotes, Bolin et al. published an extensive LCA on the impact of creosote for the use in rail ties in the USA [13]. Due to a large difference in functional units, the functional units of their study and this study were converted to tonne creosote used. When their GHG emissions of $2700 \mathrm{~kg} \mathrm{CO}_{2}$ eq per year per mile of railroad is converted, it results in $23.4 \mathrm{~kg} \mathrm{CO}$ eq per tonne creosote, which is the same order of magnitude as our finding of $9.07 \mathrm{~kg} \mathrm{CO}_{2}$ eq per tonne creosote used. The final greenhouse gas savings that are obtained by replacing fossil-based creosotes with bio-based pyrolytic sugars is $82 \%$.

Even though this LCA was based on real data from an existing pyrolysis plant rather than using models or simulations, the fractionation and wood modification treatment was still at pilot scale. The uncertainty in the results would be decreased when the process is run at a large scale and real data can be used. Finally, a significant part of the environmental impact originates from the ash treatment, which is currently modeled as a wood ash waste treatment. Other alternatives could decrease the environmental impact of the system, for example, the ash could be used to return the nutrient back to the forest or to enhance the quality of certain soils [28].

The current study presented the first full LCA on pyrolysis oil using real data on a demo plant scale. The results show that there was currently sufficient data available to complete an LCA on pyrolysis oil applications, and that in this particular case uncertainties could be limited to such an extend that meaningful conclusions could be drawn. However, only one material application was investigated. The other fractions of the pyrolysis oil were out of the scope of this article. These streams could be used for other applications in order to provide a portfolio of products based on a pyrolysis oil platform. This LCA opened the way to explore the impact of other biobased solutions that stem from the pyrolysis oil platform, such as phenolic resins, insulation foams, sand molding resins or biofuels. Future work is 
directed at determining the environmental impact of these systems and the environmental benefits of replacing current fossil-based systems with a sustainable pyrolysis oil platform.

\section{Conclusions}

This study shows that there was currently sufficient data available to complete an LCA on pyrolysis oil applications, and that in this particular case uncertainties could be limited to such an extent that meaningful conclusions could be drawn. The results show that, when forestry residues and maize digestate were compared as feedstock for pyrolysis oil production, the use of maize digestate had significantly higher environmental impact for two of the three determined impact categories. These were damage to human health (10 times higher) and resource scarcity (2.6 times higher). This increased impact was attributed to the lower energetic yield and higher ash production from the pyrolysis process on maize digestate. When pyrolytic sugars were compared to fossil-based creosote for wood modification, pyrolytic sugars showed significantly lower impacts for two of the three determined impact categories, i.e., damage to human health (7.4 times lower) and damage to resource scarcity (1.7 times lower). This lower impact was attributed to lower greenhouse gas emissions (reduction of $82 \%$ ) and the avoidance of the use of toxic creosotes. The impact on ecosystems did not change significantly because the largest impact originates from the use of the wooden pole itself. In a sensitivity analysis the selection of the choice in end of life was shown to have no influence on the conclusions. Thus, the use of forestry residues for pyrolysis oil production had a lower environmental impact than the use of maize digestate, and the use of pyrolytic sugars as wood modification treatment had a lower environmental impact than the use of fossil creosotes. This study had shown that pyrolysis oil was a sustainable alternative to the currently used creosotes for modified wooden poles using an LCA methodology. Moreover, the current study presented the first full LCA on pyrolysis oil using real data on a demo plant scale. This opened the pathway to develop a pyrolysis oil platform of biobased products that could replace fossil-based products in a sustainable matter and provided information on how to assess the sustainability of these new biobased products. Future work is directed at determining the environmental impact of these systems and the environmental benefits of replacing current fossil-based systems with a sustainable pyrolysis oil platform.

Supplementary Materials: The following are available online at http:/www.mdpi.com/2076-3417/9/20/4233/s1, Table S1: Midpoint scores for 1 GJ of pyrolysis oil. Table S2: Midpoint scores for $1 \mathrm{~m}^{3}$ a treated wood pole. Document S3: LCA review statement by Blonk Consultants.

Author Contributions: Conceptualization, P.R., C.W. and E.B.; Methodology, J.S., P.R. and M.V.; Investigation, J.S. and M.V.; Resources, T.W., S.P.W.H. and M.V.; Writing - Original Draft Preparation, J.S. and T.W.; Writing-Review \& Editing, S.P.W.H.; Visualization, S.P.W.H.; Supervision, C.W., E.B. and P.R.; Project Administration, P.R.; Funding Acquisition, P.R., C.W., E.B. and S.P.W.H.

Funding: The project 'Groen Goud' was executed as part of the INTERREG-program Deutschland-Nederland and financially supported by the European Union, the Dutch ministry of Economic Affairs, the MWEIMH NRW and the province Overijssel. The project 'Bio4Products' has received funding from the European Union's Horizon 2020 research and innovation programme under grant agreement No. 723070.

Acknowledgments: Data visualization was aided by Daniel's XL Toolbox addin for Excel, version 7.3.2, by Daniel Kraus, Würzburg, Germany (www.xltoolbox.net).

Conflicts of Interest: BTG Biomass Technology Group has a commercial interest in pyrolysis oil, which is covered by submitting the LCA to an external review before submitting the article to the peer review of this journal. The other authors declare no conflict of interest.

\section{References}

1. Murphy, B.L.; Brown, J. Environmental forensics aspects of PAHs from wood treatment with creosote compounds. Environ. Forensics 2005, 6, 151-159. [CrossRef]

2. Gallego, E.; Roca, F.J.; Perales, J.F.; Guardino, X.; Berenguer, M.J. VOCs and PAHs emissions from creosote-treated wood in a field storage area. Sci. Total Environ. 2008, 402, 130-138. [CrossRef] [PubMed] 
3. Kielhorn, J.; Mangelsdorf, I.; Medicine, E. IPCS Concise International Chemical Assessment Document 62: Coal tar creosote. IPCS Concise Int. Chem. Assess. Doc. 2004, 58, 1-113.

4. EC REGULATION (EU) No 528/2012 OF The European Parliament and of the Council of 22 May 2012 concerning the making available on the market and use of biocidal products. Off. J. Eur. Commun. 2000, 269, $1-15$.

5. Covino, S.; Fabianová, T.; Křesinová, Z.; Čvančarová, M.; Burianová, E.; Filipová, A.; Vořísková, J.; Baldrian, P.; Cajthaml, T. Polycyclic aromatic hydrocarbons degradation and microbial community shifts during co-composting of creosote-treated wood. J. Hazard. Mater. 2016, 301, 17-26. [CrossRef]

6. Wang, X.; Kersten, S.; Prins, W.; Van Swaaij, W.P.M. Biomass Pyrolysis in a Fluidized Bed Reactor. Part 1: Literature Review and Model Simulations. Ind. Eng. Chem. Res. 2005, 44, 8773-8785. [CrossRef]

7. Meier, D.; van de Beld, B.; Bridgwater, A.V.; Elliott, D.C.; Oasmaa, A.; Preto, F. State of the art of fast pyrolysis in IEA bioenergy member countries. Renew. Sustain. Energy Rev. 2013, 20, 619-641. [CrossRef]

8. Mohan, D.; Pittman, C.U.; Steele, P.H. Pyrolysis of wood/biomass for bio-oil: A critical review. Energy Fuels 2006, 20, 848-889. [CrossRef]

9. Bridgwater, A.V. Review of fast pyrolysis of biomass and product upgrading. Biomass Bioenergy 2012, 38, 68-94. [CrossRef]

10. Venderbosch, R.H. Thermochemical Processing of Biomass; Brown, R.C., Ed.; John and Wiley and Sons: Hoboken, NJ, USA, 2018; ISBN 9781119417576.

11. BTG-BTL TechnipFMC and BTG-BTL to Build Bio-Oil production in Sweden. Available online: https: //www.btg-btl.com/en/company/news/news/article?id=137 (accessed on 10 September 2019).

12. Jung, S.H.; Koo, W.M.; Kim, J.S. Fast pyrolysis of creosote treated wood ties in a fluidized bed reactor and analytical characterization of product fractions. Energy 2013, 53, 33-39. [CrossRef]

13. Bolin, C.A.; Smith, S.T. Life Cycle Assessment of Creosote-Treated Wooden Railroad Crossties in the US with Comparisons to Concrete and Plastic Composite Railroad Crossties. J. Transp. Technol. 2013, 3, 149-161. [CrossRef]

14. Iribarren, D.; Peters, J.F.; Dufour, J. Life cycle assessment of transportation fuels from biomass pyrolysis. Fuel 2012, 97, 812-821. [CrossRef]

15. Peters, J.F.; Iribarren, D.; Dufour, J. Simulation and life cycle assessment of biofuel production via fast pyrolysis and hydroupgrading. Fuel 2015, 139, 441-456. [CrossRef]

16. Dang, Q.; Yu, C.; Luo, Z. Environmental life cycle assessment of bio-fuel production via fast pyrolysis of corn stover and hydroprocessing. Fuel 2014, 131, 36-42. [CrossRef]

17. Sorunmu, Y.E.; Billen, P.; Elkasabi, Y.; Mullen, C.A.; Macken, N.A.; Boateng, A.A.; Spatari, S. Fuels and Chemicals from Equine-Waste-Derived Tail Gas Reactive Pyrolysis Oil: Technoeconomic Analysis, Environmental and Exergetic Life Cycle Assessment. ACS Sustain. Chem. Eng. 2017, 5, 8804-8814. [CrossRef]

18. Gebreslassie, B.H.; Slivinsky, M.; Wang, B.; You, F. Life cycle optimization for sustainable design and operations of hydrocarbon biorefinery via fast pyrolysis, hydrotreating and hydrocracking. Comput. Chem. Eng. 2013, 50, 71-91. [CrossRef]

19. European Commission Joint Research Centre Institute for Environment and Sustainability. Framework and Requirements for Life Cycle Impact Assessment Models and Indicators; Publications Office of the European Union: Luxembourg, 2010; ISBN 9789279175398.

20. O'Keeffe, S.; Franko, U.; Oehmichen, K.; Daniel-Gromke, J.; Thrän, D. Give them credit-the greenhouse gas performance of regional biogas systems. GCB Bioenergy 2019, 11, 791-808. [CrossRef]

21. Wang, H.; Wang, L.; Shahbazi, A. Life cycle assessment of fast pyrolysis of municipal solid waste in North Carolina of USA. J. Clean. Prod. 2015, 87, 511-519. [CrossRef]

22. Han, J.; Elgowainy, A.; Dunn, J.B.; Wang, M.Q. Bioresource Technology Life cycle analysis of fuel production from fast pyrolysis of biomass. Bioresour. Technol. 2013, 133, 421-428. [CrossRef]

23. Hsu, D.D. Life cycle assessment of gasoline and diesel produced via fast pyrolysis and hydroprocessing. Biomass Bioenergy 2012, 45, 41-47. [CrossRef]

24. Hauschild, M.; Goedkoop, M.; Guinee, J.; Heijungs, R.; Huijbregts, M.; Jolliet, O.; Margni, M.; De Schryver, A. Recommendations for Life Cycle Impact Assessment in the European Context; Publication Office of the European Union: Luxemburg, 2011. [CrossRef] 
25. Kohler, M.; Kunniger, T. Emissions of polycyclic aromatic hydrocarbons (PAH) from creosoted railroad ties and their relevance for life cycle assessment (LCA). Holz Roh Werkst. 2003, 61, 117-124. [CrossRef]

26. Otten, M.B.J.; Bergsma, G.C. Beter één AVI met een hoog rendement dan één dichtbij. 2010. Available online: https://www.ce.nl/publicaties/1096/beter-een-avi-met-een-hoog-rendementdan-een-dichtbijhoeveel-transport-van-afval-is-nuttig-voor-een-hoger-energierendement (accessed on 10 September 2019).

27. Huijbregts, M.A.J.; Steinmann, Z.J.; Elshout, P.M.F.; Stam, G.; Verones, F.; Vieira, M.D.M.; Zijp, M.; van Zelm, R. ReCiPe 2016: A Harmonized Life Cycle Impact Assessment Method at Midpoint and Enpoint Level-Report 1: Characterization; National Institute for Public Health and the Environment: Bilthoven, The Netherlands, 2016; p. 194.

28. Brandón, M.G.; Juárez, M.F.-D.; Insam, H. D6.3 Ash Characterization. 2017. Available online: https: //www.residue2heat.eu/d6-3-ash-characterization/ (accessed on 10 September 2019).

(C) 2019 by the authors. Licensee MDPI, Basel, Switzerland. This article is an open access article distributed under the terms and conditions of the Creative Commons Attribution (CC BY) license (http://creativecommons.org/licenses/by/4.0/). 